\title{
Serum Procalcitonin is a sensitive and specific marker in the diagnosis of septic arthritis and acute osteomyelitis
}

Karthikeyan Maharajan ${ }^{*}$, Dilip Kumar Patro', Jagdish Menon ${ }^{1}$, Ananthanarayanan Palghat Hariharan², Sabhash Chandra Parija ${ }^{3}$, Murali Poduval ${ }^{1}$ and Sreenivas Thimmaiah ${ }^{1}$

\begin{abstract}
Background: Early diagnosis of Acute Osteomyelitis (OM) and Septic Arthritis (SA) is of vital importance to avoid devastating complications. There is no single laboratory marker which is sensitive and specific in diagnosing these infections accurately. Total Count, ESR and CRP are not specific as they can also be elevated in non pyogenic causes of inflammation. Pus Culture and sensitivity is not a true gold standard due to its varied positivity rates (40 - 70\%). Serum Procalcitonin (PCT), at $0.5 \mathrm{ng} / \mathrm{ml}$ is found to be an accurate marker for pyogenic infections. The objectives of this study were to show that PCT is an accurate marker in differentiating Acute Osteomyelitis and Septic Arthritis from viral and non infective inflammatory bone and joint conditions.

Methods: Patients of all age groups $(n=82)$ with suspected Acute Osteomyelitis and Septic Arthritis were prospectively included in this study. All patients were subjected to TC, CRP, PCT, IgM Dengue, IgM Chikungunya, pus and blood culture and sensitivity. At the end of the study, patients were classified into 3 groups: Group 1 = Confirmed Pyogenic $(n=27)$; Group 2 = Presumed Pyogenic $(n=21)$; Group 3 = Non - infective inflammatory $(n=34)$.

Results: Group 1 has higher mean PCT levels than Group 2 and $3(p<0.05)$. PCT, at $0.4 \mathrm{ng} / \mathrm{ml}$, was $85.2 \%$ sensitive and $87.3 \%$ specific in diagnosing Septic Arthritis and Acute Osteomyelitis. In comparison, PCT at conventional cut - off of $0.5 \mathrm{ng} / \mathrm{m} /$ is $66.7 \%$ sensitive and $91 \%$ specific.

Conclusion: Serum Procalcitonin, at a cut - off of $0.4 \mathrm{ng} / \mathrm{ml}$, is a sensitive and specific marker in the diagnosis of Septic Arthritis and Acute Osteomyelitis.
\end{abstract}

Keywords: Serum, Procalcitonin, Septic, Arthritis, Acute, Osteomyelitis, Diagnosis, Inflammatory, Marker

\section{Background}

Acute bone and joint infections are truly a diagnostic enigma in the Emergency Department. Management of these focuses on providing a rapid etiologic diagnosis since therapies and outcome vary widely depending upon the cause. Delayed diagnosis and treatment leading to disabling sequelae are not uncommon. Functional disabilities occur in 25 to $50 \%$ of cases and can even be life threatening in 5 to $15 \%$ of cases [1-3]. Total Count (TC), Erythrocyte Sedimentation Rate (ESR) and C - Reactive Protein (CRP) are routinely used in the diagnosis of these infections but no specific laboratory test exists

\footnotetext{
* Correspondence: drkarthik_ortho_jipmer@yahoo.in

'Department of Orthopedics, JPMER, Puducherry, India

Full list of author information is available at the end of the article
}

with the exception of isolation of pathogenic organism from the bone or synovial fluid [4,5]. A positive culture result has high specificity but even this cannot be considered as gold standard because it lacks sensitivity (only 40-60\%) and the results are available only after 2 to 3 days [2,3]. Despite this fact, culture is being used by many researchers as positive gold standard and patients without any clinical evidence plus negative culture as negative gold standard. The lack of sensitive laboratory markers or a gold standard investigation for diagnosing bacterial infections clinically has contributed to the overuse of antibiotics especially in neonates and elderly patients where clinical signs could be very subtle. The concept of providing antibiotics for every suspected

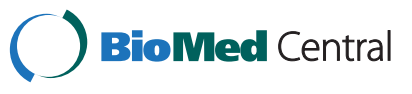


infection is slowly being withdrawn because of emerging issues with antimicrobial resistance.

In this regard, there is a need for a biochemical marker which shows high sensitivity and specificity in diagnosing infection and also as a guide for starting antibiotics. There is now enough evidence to support the role of Procalcitonin (PCT) as a diagnostic and prognostic marker in infective conditions with its very high specificity for bacterial infections [6-9]. On the contrary, there are only very few studies evaluating its efficacy in Septic Arthritis (SA) and Acute Osteomyelitis (OM) with varying results [10-14]. Serum levels of Procalcitonin is very low in healthy individuals $(<0.1 \mathrm{ng} / \mathrm{ml})$ and increases rapidly in response to bacterial endotoxin $[15,16]$. These properties together with a half life of 22 to 29 hours have made Procalcitonin, a convenient tool to monitor serious infections and to discriminate bacterial infections from viral and non infective inflammatory conditions $[17,18]$. Owing to its high specificity, Procalcitonin can also be used as a guide for starting antibiotics and monitoring treatment $[19,20]$.

Hence this study was conducted prospectively with the objectives to show that PCT is an accurate marker in the diagnosis of Acute Osteomyelitis and Septic Arthritis. Early treatment can be started which can decrease the incidence of disabling sequelae.

\section{Materials and methods}

This study was conducted in the Department of Orthopaedics, in a 1200 bedded tertiary health - care centre from January 2010 to June 2011. We included all cases of suspected acute (less than 2 weeks) synovitis / arthritis and osteomyelitis of all age groups with no evidence of infection elsewhere. We excluded (1) all cases of chronic arthritis and chronic osteomyelitis; (2) cases where antibiotics were given before presenting to us. (3) cases with foci of infection elsewhere. (4) immunocompromised hosts. The study was approved by Institute Research council and Ethics Committee and conducted in accordance to the standards of Declaration of Helsinki, 1964. Detailed informed consent was obtained from all patients or from parents and legal guardians included in this study.

All patients were assessed for clinical parameters which included presence of swelling; joint effusion; tenderness; local warmth; deformity; range of movement restriction and presence of septicemic symptoms. Detailed proforma was used to record patient details and clinical findings. Plain radiography [Anteroposterior and Lateral views] and Ultrasound (USG) of the involved bone and joint were done. Under adequate anesthesia and proper aseptic precautions, Aspiration was done using $18 \mathrm{G}$ needle from the joint and bone with subperiosteal abscess. In the absence of subperiosteal abscess, aspirate was obtained by drilling the bone with $2 \mathrm{~mm}$ drill bit under anesthesia. This was followed by definitive surgery in the form of arthrotomy or incision and drainage (I\&D).

Aspirate was immediately processed for the presence of pus cells, gram staining, culture and sensitivity $(C / S)$. All patients were subjected to Blood C/S. Culture and sensitivity was considered as the gold standard in this study. Laboratory analyses included estimation of ESR, TC, CRP, Procalcitonin, IgM Dengue and IgM Chikungunya. ESR was estimated using Wintrobe's method. CRP was measured using Nephelometer [BNPROSPEC, Germany]. The cut-off in our laboratory was $3.02 \mathrm{mg} / \mathrm{l}$ above which CRP was considered positive. PCT was determined by Quantitative Immunoluminetric test [LUMItest, BRAHMS Diagnostica, Berlin, Germany) by the investigator who followed the assay manufacturer's recommendations. The threshold for PCT detection defined by our laboratory is $0.1 \mathrm{ng} / \mathrm{ml}$. Samples were analyzed for IgM Dengue and IgM Chikungunya using ELISA technique. Dengue and Chikungunya are the commonest viral infections presenting with bone and joint symptoms in our region and the only feasible tests available in our institution. They were performed to rule out viral etiology for acute bone and joint infective conditions.

At the end of the study, patients were divided into three groups: Confirmed Pyogenic group (Group 1), Presumed Pyogenic group (Group 2) and Non-Infective inflammatory group (Group 3) based on the above parameters. In Group 1, there was a high clinical suspicion of infection and pus was aspirated. Pus and/or blood culture was positive for bacteria and patients received full course of antibiotics [ 2 weeks of sensitive IV antibiotics and 6 weeks of oral antibiotics]. This group included Culture Positive Septic Arthritis (Group 1a) and Culture Positive Acute Osteomyelitis (Group 1b). In Group 2, there was clinical suspicion of infection and altered synovial fluid was aspirated while aspirate / blood culture remained negative and these patients too were treated with full course of antibiotics due to clinical suspicion of infection. This group included culture negative septic arthritis (Group 2a) and culture negative acute osteomyelitis (Group 2b). In Group 3, patients had acute symptoms pertaining to bone and joint but there was no suspicion of infection clinically (acute synovitis due to rheumatoid arthritis, juvenile rheumatoid arthritis, gout, trauma, transient synovitis of hip, sickle cell bone crisis and nonspecific causes). Synovial fluid was aspirated and aspirate culture remained negative and hence these patients were not started on any antibiotics (Table 1).

Mean levels of TC, ESR, CRP and PCT were compared between these groups and sensitivity, specificity and predictive values of PCT were assessed.

The statistical significance of all parameters (TC, ESR, CRP and PCT) were analyzed using Independent Students $T$ test and One Way ANOVA with BonFerroni PostHoc 
Table 1 Patient Characteristics $\mathbf{n}=\mathbf{8 2}$

\begin{tabular}{|c|c|}
\hline Parameter & Value \\
\hline Symptom duration (days) $)^{*}$ & $3(2-5)$ \\
\hline Males / Females & $58 / 24$ \\
\hline Age (years) ${ }^{*}$ & 25.33 (10 days -86 years) \\
\hline \multicolumn{2}{|l|}{ Group } \\
\hline Confirmed pyogenic $(\mathrm{C}+\mathrm{SA} / \mathrm{C}+\mathrm{OM})$ & $27(19 / 8)$ \\
\hline Presumed pyogenic (C-SA / C-OM) & $21(17 / 4)$ \\
\hline Non - infective inflammatory & 34 \\
\hline RA & 8 \\
\hline Juvenile RA & 4 \\
\hline Gout & 2 \\
\hline Transient synovitis of hip & 5 \\
\hline Trauma & 7 \\
\hline Sickle cell crisis & 1 \\
\hline Non - specific synovitis ${ }^{\phi}$ & 7 \\
\hline Blood C / S & $3(11.11 \%)$ \\
\hline Pus C / S (C+SA / C+OM) & $27(19 / 8)$ \\
\hline Methicillin Resistant SA & $20(12 / 8)$ \\
\hline Staphylococcus aureus & $3(3 / 0)$ \\
\hline Coagulase negative SA & $1(1 / 0)$ \\
\hline Pseudomonas aeruginosa & $1(1 / 0)$ \\
\hline Klebsiella pneumonia & $1(1 / 0)$ \\
\hline Streptoccus species & $1(1 / 0)$ \\
\hline
\end{tabular}

* values expressed as median; $¥$ value expressed as mean; $\phi$ Non specific synovitis = where cause cannot be found; $R A$ Rheumatoid Arthritis, $C+S A$ culture positive Septic arthritis, $C+O M$ culture positive acute osteomyelitis, C-SA culture negative Septic Arthritis, C-OM culture negative acute osteomyelitis, C/S culture \& sensitivity, SA Staphylococcus aureus.

test. The sensitivity, specificity and predictive values were analyzed using SPSS software version 19. Newcombe method was used to calculate $95 \%$ confidence intervals (CI). $p<0.05$ was considered statistically significant.

\section{Results}

A total of 106 patients presented with clinical presentations suggestive of OM and SA. Out of these, 24 patients were excluded from the study as 11 patients gave a history of antibiotic administration before presentation and 13 patients had other foci of infection. The study group included 82 patients of all age groups (Table 1). The youngest was a 10 days old neonate and the oldest was 86 years of age with the mean age of 25.33 years. 23 patients $(28.04 \%)$ were less than 5 years of age and 28 patients $(34.14 \%)$ were above 40 years. Out of 82 patients, there were 58 males $(70.73 \%)$ and 24 females (29.26). Blood culture was positive (11.11\%) for MRSA in three cases, two cases of SA involving Hip joint and one case of OM of Distal Femur. MRSA was the commonest organism isolated from pus. It was positive in $74.07 \%$ of patients in Group 1; 63.16\% in Group 1a and $100 \%$ in Group 1b. Viral analysis for IgM Dengue and Chikungunya did not yield any positive results.

All data in this study follow Normal type of distribution. On comparison of mean (Table 2), Group 1 had higher mean PCT values (1.0005) than group 2 and 3 which is statistically significant $(p=0.001)$. On multivariate analysis, Group 1b has higher mean PCT values (0.8453) than Group 1a, but not statistically significant $(p=0.76)$. Group 2a has higher mean PCT levels (0.5594) than Group 2b with no statistical significance $(p=0.32)$. Patients with positive blood culture had higher mean PCT levels (1.68) but not statistically significant $(p=0.138)$. Patients who grew MRSA in the aspirate had statistically significant $(p=0.01)$ higher mean PCT levels (1.02). Similarly, patients who had positive X-ray changes [lytic lesions, erosions, dislocation] and positive ultrasound findings [presence of moving echoes in joint / subperiosteal abscess] had statistically significant higher mean PCT levels $0.82(p=0.001)$ and $1.06(p=0.001)$ respectively.

On analysis of other parameters, the mean TC and ESR were found to have raised in Group 1 and 2 with statistical significance $(p<0.05)$. In contrast, Group 1 had higher CRP levels than Group 2 which is not statistically significant $(p=0.1)$.

Sensitivity and specificity PCT at various cut - offs is depicted in Table 3. For Confirmed versus Presumed / Non - infective groups, at a cut off of $0.5 \mathrm{ng} / \mathrm{ml}$, PCT is found to be $66.7 \%$ sensitive and $91 \%$ specific $(\mathrm{PPV}=$ $78.2 \%$; NPV $=84.7 \%$ ) in diagnosing culture positive pyogenic infections. But at $0.4 \mathrm{ng} / \mathrm{ml}$, it is $85.2 \%$ sensitive and $87.3 \%$ specific $(\mathrm{PPV}=76.6 \%$; NPV $=92.3 \%)$. Levels lower than this has high sensitivity but low specificity and vice versa. So a cut off at which sensitivity and specificity got balanced was taken in this study. For

Table 2 Mean with SD for all parameters

\begin{tabular}{cccccc}
\hline Parameter & Group & N & Mean & S.D & P - value \\
\hline TC & Confirmed & 27 & 9311.11 & 1531.05 & $\mathbf{0}$ \\
& Presumed & 21 & 8600 & 1063.01 & \\
ESR & Non-pyogenic & 34 & 7279.41 & 1328.65 & \\
& Confirmed & 27 & 61.85 & 10.55 & $\mathbf{0}$ \\
& Presumed & 21 & 51.57 & 12.96 & \\
CRP & Non-pyogenic & 34 & 21.53 & 11.778 & \\
& Confirmed & 27 & 12.35 & 5.77 & $\mathbf{0 . 0 1 4}$ \\
& Presumed & 20 & 11.31 & 4.56 & \\
& Non-pyogenic & 9 & 6.44 & 3.74 & $\mathbf{0}$ \\
& Confirmed & 27 & 1.00 & 0.73 & \\
& Presumed & 21 & 0.53 & 0.46 & \\
& Non-pyogenic & 34 & 0.15 & 0.05 & \\
\hline
\end{tabular}

TC Total Count, ESR Erythrocyte Sedimentation Rate, CRPC - Reactive Protein, $P C T$ Procalcitonin. 


\begin{tabular}{|c|c|c|c|c|}
\hline \multirow[t]{2}{*}{$\begin{array}{l}\text { PCT } \\
\text { level }\end{array}$} & \multicolumn{2}{|c|}{$\begin{array}{c}\text { Confirmed / presumed Vs } \\
\text { non infective }\end{array}$} & \multicolumn{2}{|c|}{$\begin{array}{l}\text { Confirmed Vs presumed / } \\
\text { infective }\end{array}$} \\
\hline & Sensitivity \% & Specificity \% & Sensitivity \% & Specificity \% \\
\hline 0.1 & 100 & 9.1 & 100 & 14.7 \\
\hline 0.21 & 96.3 & 56.4 & 97.9 & 91.2 \\
\hline 0.27 & 88.9 & 67.3 & 85.4 & 97.9 \\
\hline 0.3 & 88.9 & 74.5 & 77.1 & 97.9 \\
\hline 0.32 & 88.9 & 81.8 & 68.8 & 97.9 \\
\hline 0.34 & 83.7 & 83.6 & 66.7 & 100 \\
\hline 0.4 & 85.2 & 87.3 & 62.5 & 100 \\
\hline 0.45 & 74.4 & 90.9 & 50 & 100 \\
\hline 0.5 & 66.7 & 90.9 & 47.9 & 100 \\
\hline 0.6 & 55.6 & 90.9 & 41.7 & 100 \\
\hline 0.7 & 51.9 & 90.9 & 37.5 & 100 \\
\hline 0.8 & 51.9 & 92.7 & 35.4 & 100 \\
\hline 0.9 & 48.1 & 94.5 & 33.3 & 100 \\
\hline 1 & 44.4 & 94.5 & 31.3 & 100 \\
\hline
\end{tabular}

Confirmed / Presumed versus Non - infective groups, PCT is $47.9 \%$ sensitive and $100 \%$ specific (PPV $=100 \%$; $\mathrm{NPV}=57.6 \%)$ in diagnosing clinically suspected infection at $0.5 \mathrm{ng} / \mathrm{ml}$ while it is $62.5 \%$ sensitive and $100 \%$ specific $(\mathrm{PPV}=100 \%$; NPV $=65.4 \%)$ at $0.4 \mathrm{ng} / \mathrm{ml}$. For confirmed pyogenic versus non-pyogenic, at a cut - off of $0.4 \mathrm{ng} / \mathrm{ml}$, PCT is $85.17 \%$ sensitive and $100 \%$ specific with PPV and NPV of $100 \%$ and $93.8 \%$ respectively (Table 4).

Area Under the Curve (AUC) on plotting Receiver Operating Curves (ROC) was $0.886(\mathrm{~S} . \mathrm{E}=0.04)$ for Confirmed versus Presumed / Non - infective groups while AUC is 0.976 (S.E $=0.016$ ) for Confirmed / Presumed versus Non - infective groups (Figure 1).

\section{Discussion}

Septic Arthritis and Acute Osteomyelitis are relatively common entities in day to day orthopedic practice and in a tertiary referral centre like ours, it is more common.
But the diagnosis of these infections faces the following problems: inadvertent use of antibiotics by the physician who first sees the patient before the proper diagnosis is made; pus culture and sensitivity which is often considered the gold standard is not a useful gold standard because of its low positivity rates; absence of a single laboratory parameter with high specificity and sensitivity; dubious presentations of these infections in the very young and the old; hence the search for a realistic laboratory marker is essential.

Many of the complications secondary to delayed diagnosis have come down in number due to the availability of powerful antibiotics but on the other hand this has led to the emergence of anti- microbial resistance due to its inadvertent and irrational use. This is of serious concern because practically only few drugs are available as of now to tackle serious infections [21-23]. PCT has been found to be a promising marker in diagnosing bacterial infections with its high specificity. Its usefulness over markers like TC, ESR and CRP has been described in several conditions like sepsis, upper respiratory tract infections, pneumonias, pancreatitis, pyelonephritis, burns and in various other conditions $[18,24,25]$. With this background, this study was conducted with the following objectives: To show that PCT is an accurate marker for differentiating $\mathrm{OM}$ and SA from viral infections and non infective inflammatory bone and joint conditions and to evaluate Sensitivity, Specificity and Predictive values of Serum Procalcitonin in diagnosing OM and SA.

Pus culture is expected to be positive in 40 to $60 \%$ in patients of SA and OM though it is $100 \%$ specific $[2,3]$. In the present study, pus culture positivity is $56.25 \%$. Staphylococcus aureus was described as the most common identifiable causative organism which accounts for more than $50 \%$ of isolated organism in acute hematogenous osteomyelitis and $30 \%$ in septic arthritis. MRSA is the commonest organism in the present study isolated in $74.07 \%$ of cases $(63.16 \%$ of septic arthritis cases and $100 \%$ of acute osteomyelitis). Serum PCT level less than $0.5 \mathrm{ng} / \mathrm{ml}$ is considered normal $[15,17]$. However, there is no unanimous agreement in deciding the cut - off because PCT is an emerging diagnostic marker and is either undetectable or

Table 4 Sensitivity, Specificity and Predictive values of PCT at 0.5 and $0.4 \mathbf{n g} / \mathbf{m l}$

\begin{tabular}{ccccccc}
\hline Groups & PCT $(\mathbf{n g} / \mathbf{m l})$ & Sensitivity \% 95\% Cl & Specificity \% 95\% Cl & PPV \% 95\% Cl & NPV \% 95\% Cl & LR \\
\hline Confirmed Pyogenic vs presumed + & 0.5 & $66.7(46-83.4)$ & $91(80-97)$ & $78.2(56-92.5$ & $84.7(73-92.5)$ & 7.33 \\
Non - pyogenic & 0.4 & $85.2(66.3-95.8)$ & $87.3(75.5-94.7)$ & $76.6(57.7-90.1)$ & $92.3(81.5-98)$ & 6.69 \\
Confirmed+ Presumed vs non - pyogenic & 0.5 & $47.9(33.2-62.8)$ & $100(89.7-100)$ & $100(85.2-100)$ & $57.6(44.1-70.4)$ & $*$ \\
& 0.4 & $62.5(47.4-76)$ & $100(89.7-100)$ & $100(88.4-100)$ & $65.4(60-78)$ & $*$ \\
Confirmed vs non - pyogenic & 0.5 & $66.67(46-83.4)$ & $100(91.2-100)$ & $100(87.4-100)$ & $86.3(77.8-94.9)$ & $*$ \\
& 0.4 & $85.19(66.3-95.8)$ & $100(90.2-100)$ & $100(88.7-100)$ & $93.8(82.7-96.5)$ & $*$ \\
\hline
\end{tabular}



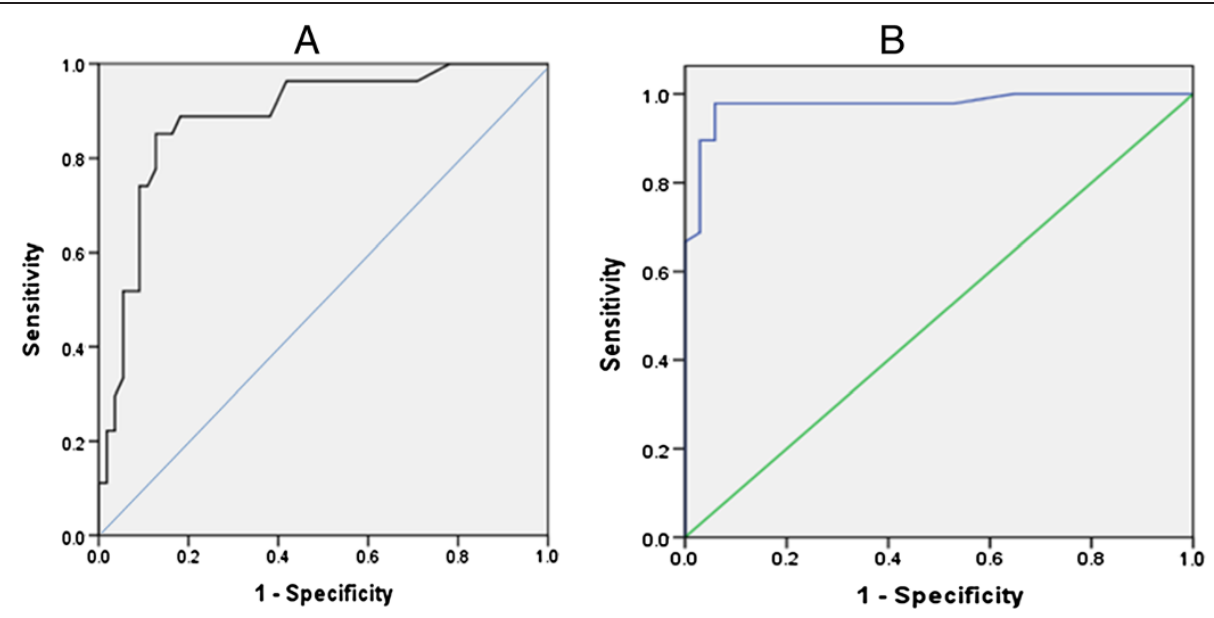

Figure 1 ROC for PCT.

very low in healthy individuals. Studies by Butbul Aviel et al., [10]; Fottner et al., [11]; Martinot et al., [13] and Faesh et al., [14] have taken $0.5 \mathrm{ng} / \mathrm{ml}$ as cut - off above which it is considered as a marker of pyogenic infection. However, study by Hogle et al., [12] has taken $0.25 \mathrm{ng} / \mathrm{ml}$ as the cutoff. This reflects the absence of a general consensus in deciding the cut-off.

In the present study, the sensitivity, specificity, positive predictive value and negative predictive value of PCT was assessed at $0.5 \mathrm{ng} / \mathrm{ml}$ and $0.4 \mathrm{ng} / \mathrm{ml}$. For confirmed pyogenic versus presumed / non pyogenic, at $0.4 \mathrm{ng} / \mathrm{ml}$,
PCT is $85.2 \%$ sensitive and $87.3 \%$ specific in diagnosing culture positive SA and OM (Figure 2) with PPV and NPV of $76.6 \%$ and $92.3 \%$ respectively. The balancing of sensitivity and specificity is essential for testing any new diagnostic marker and hence $0.4 \mathrm{ng} / \mathrm{ml}$ is taken as the cut-off in this study. For confirmed / presumed pyogenic versus non-pyogenic, at a cut - off of $0.4 \mathrm{ng} / \mathrm{ml}, \mathrm{PCT}$ is $62.5 \%$ sensitive and $100 \%$ specific in diagnosing clinically positive infection with PPV and NPV of 100\% and 65.4\% respectively. For confirmed pyogenic versus non-pyogenic, at a cut - off of $0.4 \mathrm{ng} / \mathrm{ml}$, PCT is $85.17 \%$ sensitive and

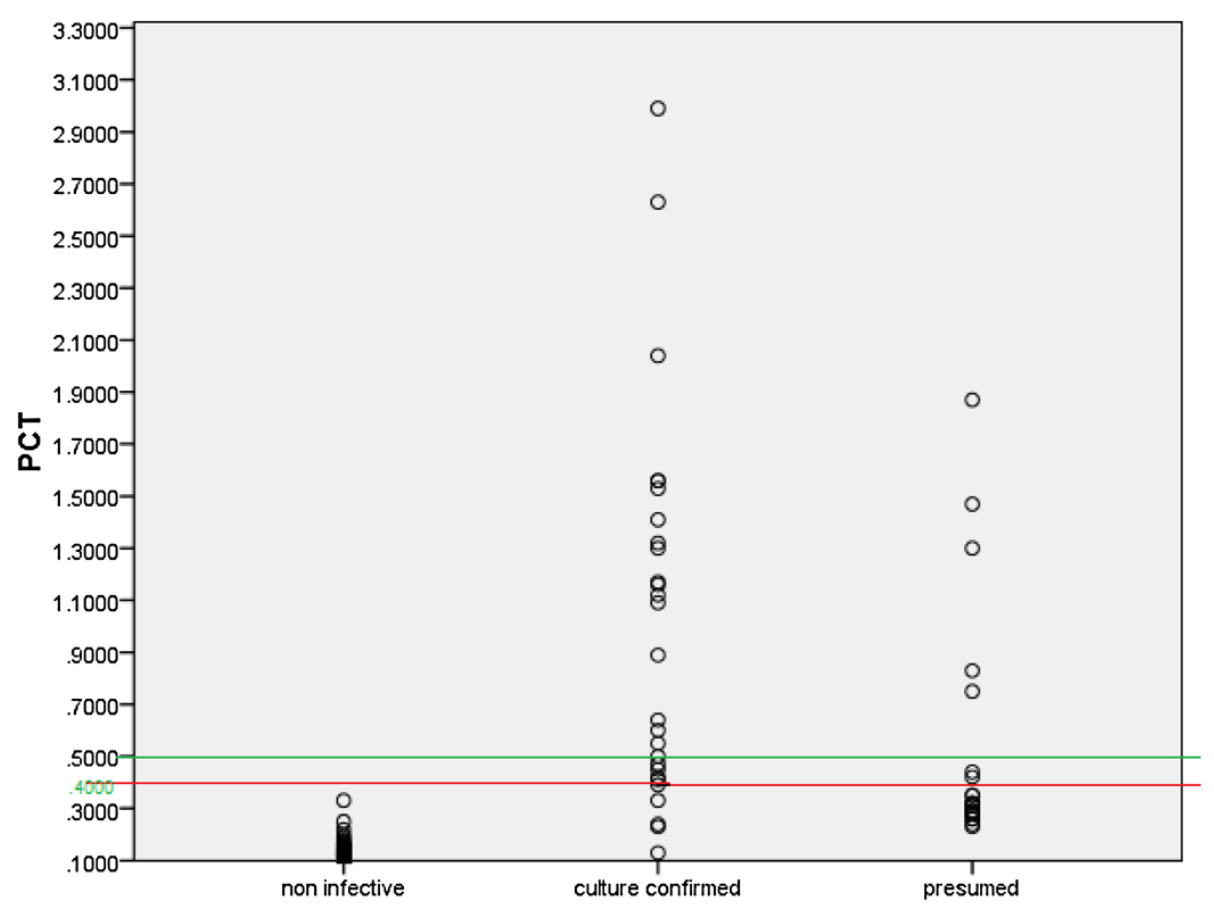

Figure 2 Scatter diagram plotting the distribution of patients with respect to PCT cut-offs. 
$100 \%$ specific in diagnosing clinically positive infection with PPV and NPV of $100 \%$ and $93.8 \%$ respectively.

There are only few studies evaluating the efficacy of PCT in SA and OM. Butbul Aviel et al., [10] in 2005, have shown that $\mathrm{PCT}$ at $0.5 \mathrm{ng} / \mathrm{ml}$ was a poorly sensitive but highly specific marker using a semi quantitative PCT card test with higher sensitivity for OM than SA. However, we have not attempted to analyze separately for SA and OM as PCT as a marker can diagnose only the presence and severity of infection and is not influenced by the site of infection. Similarly, studies by Fottner et al., [11]; Martinot et al., [13] and Sabine Faesch et al., [14] have shown PCT as a poorly sensitive marker with high specificity at a cut-off of $0.5 \mathrm{ng} / \mathrm{ml}$. This could be due to the low sample size as reflected in all these studies. The study by Hogle et al., [12] has shown PCT as a highly sensitive marker but low specific marker at a cut-off of $0.25 \mathrm{ng} / \mathrm{ml}$. The present study has included 36 patients of SA and 12 patients of OM which is considerably higher when compared to other studies. The present study has shown equally high sensitivity and specificity when compared to other groups. The strengths of the present study are: Prospective study; the number of patients with septic arthritis and acute osteomyelitis are more when compared to other studies; this study has included patients of all age groups; the LUMItest [BRAHMS Diagnostica] used has a very low detection limit of $0.1 \mathrm{ng} /$ $\mathrm{ml}$. The limitation of our study is that overall sample size is low but not to extent of affecting statistical analysis. We have included patients all age groups ( 10 days old to 86 years). Though this might have an impact on sensitivity and specificity rates, majority of patients $(66 \%)$ in our study were less than 40 years. Through this study, we would also like to show that adult septic arthritis is not an uncommon entity, atleast in our parts of the world. Ours is a tertiary referral hospital catering to different referral patterns. Though this might have an impact on the result of this study, it is less likely as we stringently followed our inclusion criteria. We have included only cases of dengue and chikungunya as these are the only relevant viral infections common in our region but these may not be common in other parts of the world. The present study was designed to assess the diagnostic value of PCT. Hence serial PCT measurements which will help us to study its prognostic significance were not done.

\section{Conclusion}

The present study has shown that Serum Procalcitonin, at a cut - off of $0.4 \mathrm{ng} / \mathrm{ml}$, is a sensitive and specific marker in the diagnosis of Acute Osteomyelitis and Septic Arthritis. This is in comparison to the conventional cut - off of $0.5 \mathrm{ng} / \mathrm{ml}$ which is specific but less sensitive. Thus, Serum Procalcitonin may be used as a new diagnostic marker for initiation of treatment in the management of Acute Osteomyelitis and Septic arthritis.

\section{Abbreviations}

SA: Septic arthritis; OM: Acute osteomyelitis; TC: Total count; ESR: Erythrocyte sedimentation rate; CRP: $\mathrm{C}$ - reactive protein; $\mathrm{PCT}$ : Procalcitonin.

\section{Competing interests}

The authors declare that they have no competing interests.

\section{Authors' contributions}

KM conducted the study. DKP, JM and MP guided in grouping the patients, AHP in Procalcitonin estimation, SCP in viral markers analysis, STM in the preparation of this manuscript. All authors have read and approved the final version of this manuscript.

\section{Acknowledgements}

We would like to acknowledge the efforts of Dr.Harichandrakumar, consultant biostatistician for helping us in the statistical analysis of data.

\section{Author details}

${ }^{1}$ Department of Orthopedics, JIPMER, Puducherry, India. ${ }^{2}$ Department of Biochemistry, JIPMER, Puducherry, India. ${ }^{3}$ Department of Microbiology, JIPMER, Puducherry, India.

Received: 3 December 2011 Accepted: 28 June 2013

Published: 4 July 2013

\section{References}

1. Georgens ED, McEvoy A, Watson M, Barrett IR: Acute osteomyelitis and septic arthritis in children. J Paediatr Child Health 2005, 41:59-62.

2. Morrey BF, Bianco AJ Jr, Rhodes KH: Septic arthritis in children. Orthop Clin North Am 1975, 6(4):923-934.

3. Mathews CJ, Weston VC, Jones A, Field M, Coakley G: Bacterial septic arthritis in adults. Lancet 2010, 375:846-855.

4. Unkila-Kallio L, Kallio MJ, Eskola J, Peltola H: Serum C - reactive protein, erythrocyte sedimentation rate, and white blood cell count in hematogenous osteomyelitis of children. Pediatrics 1994, 93:59-62.

5. Levine MJ, McGuire KJ, McGowan KL, Flynn JM: Assessment of the test characteristics of $\mathrm{C}$ - reactive protein for septic arthritis in children. J Pediatr Orthop 2003, 23:373-377.

6. Crain M, Muller B: Procalcitonin in bacterial infections- hype, hope, more or less? Swiss Med Wkly 2005, 135:451-460.

7. Gendrel D, Bohoun C: Procalcitonin in pediatrics for differentiation for bacterial and viral infections. Intensive Care Med 2000, 26:178-181.

8. Ghorbani G: Procalcitonin role in differential diagnosis of infection stages and non infection inflammation. Pak J Biol Sci 2009, 15(12(4)):393-396.

9. Chan YL, Tseng CP, Tsay PK, Chang SS, Chiu TF: Procalcitonin as a marker of bacterial infection in the emergency department: an observational study. Critical Care 2004, 8:1.

10. Butbul Y, Koren A, Halevy R, Sakran W: Procalcitonin as a diagnostic aid in osteomyelitis and septic arthritis. Pediatric Emer Care 2005, 21(12):828-832.

11. Fottner A, Birkenmaier C, von Schulze PC, Wegener B, Jansson V: Can serum procalcitonin help to differentiate between septic and nonseptic arthritis? Arthroscopy 2008, 24(2):229-233.

12. Hügle T, Schuetz P, Mueller B, Laifer G, Tyndall A, Regenass S, Daikeler T: Serum procalcitonin for discrimination between septic and non-septic arthritis. Clin Exp Rheumatol 2008, 26(3):453-456.

13. Martinot M, Sordet C, Soubrier M, Puéchal X, Saraux A, Lioté F: Diagnostic value of serum and synovial procalcitonin in acute arthritis: a prospective study of 42 patients. Clin Exp Rheumatol 2005, 23(3):30310.

14. Faesch S, Cojocaru B, Hennequin C, Pannier S, Glorion C: Can procalcitonin measurement help the diagnosis of osteomyelitis and septic arthritis? a prospective trial. Italian Journal of Pediatrics 2009, 35:33.

15. Barresi A, Pallotti F, d'Eril GVM: Biological variation of procalcitonin in healthy individuals. Clin Chem 2004, 50:1878.

16. Assicot M, Mackensen A, Petitjean S, Engelhardt R, Bohuon C: Kinetics of the appearance of procalcitonin following endotoxin administration. Lancet 1993, 27(341(8844)):515-518. 
17. Shimetani N, Ohba Y, Shimetani K, Mashiko T, Matsuyama N, Ohtani $\mathrm{H}_{\text {, }}$ Morii M: Assay for determination of the serum procalcitonin level: biochemical and clinical evaluation. Rinsho Byori 2001, 49(1):56-60.

18. Delevaux I, André M, Colombier M, Albuisson E, Meylheuc F, Bègue RJ: Can procalcitonin measurement help in differentiating between bacterial infection and other kinds of inflammatory processes? Ann Rheum Dis 2003, 62(4):337-340.

19. Oh JS, Kim SU, Oh YM, Choe SM, Choe GH: The usefulness of the semi quantitative procalcitonin test kit as a guideline for starting antibiotic administration. Am J Emerg Med 2009, 27(7):859-863.

20. Holub M, Rozsypal H, Chalupa P: Procalcitonin: a reliable marker for the diagnosis and monitoring of the course of bacterial infection. Klin Mikrobiol Infekc Lek 2008, 14(6):201-208.

21. Simon L, Gauvin F, Amrre DK, Louis PS, Lacroix J: Serum procalcitonin and C-reactive protein levels as markers of bacterial infection: a systematic review and meta-analysis. Clin Infect Dis 2005, 40(9):1386-1388.

22. Kite P. Millar MR, Gorham P. Congdon P: Comparison of five tests used in diagnosis of neonatal bacteraemia. Arch Dis Child 1988, 63(6):639-643.

23. Hatherill M, Tibby SM, Sykes K, Turner C, Murdoch IA: Diagnostic markers of infection: comparison of procalcitonin with $\mathrm{C}$ - reactive protein and leukocyte count. Arch Dis Child 1999, 81(5):417-421.

24. Eberhard K, Haubitz M, Brunkhorst M, Kliem V, Koch M: Usefulness of procalcitonin for differentiation between activity of systemic autoimmune disease and invasive bacterial infection. Arthritis and Rheumatism 1997, 40:7.

25. Becker KL, Snider R, Nylen ES: Procalcitonin assay in systemic inflammation, infection, and sepsis: clinical utility and limitations. Crit Care Med 2008, 36:3.

doi:10.1186/1749-799X-8-19

Cite this article as: Karthikeyan et al:: Serum Procalcitonin is a sensitive and specific marker in the diagnosis of septic arthritis and acute osteomyelitis. Journal of Orthopaedic Surgery and Research 2013 8:19.

\section{Submit your next manuscript to BioMed Central and take full advantage of:}

- Convenient online submission

- Thorough peer review

- No space constraints or color figure charges

- Immediate publication on acceptance

- Inclusion in PubMed, CAS, Scopus and Google Scholar

- Research which is freely available for redistribution 